\title{
Salvage Transrectal High-Intensity Focused Ultrasound Therapy for Patients with Recurrence of Vesico-Urethral Anastomosis after Radical Prostatectomy
}

\author{
Mutsuo Hayashi ${ }^{*}$, Tetsutaro Hayashi², Kiyotaka Oka1 ${ }^{1}$, Keisuke Goto², Ryuhei Kanaoka ${ }^{1}$ \\ ${ }^{1}$ Department of Urology, Takanobashi Central Hospital, Hiroshima, Japan \\ ${ }^{2}$ Department of Urology, Hiroshima University Hospital, Hiroshima, Japan \\ Email: *m6-hayashi@hi.enjoy.ne.jp
}

How to cite this paper: Hayashi, M., Hayashi, T., Oka, K., Goto, K. and Kanaoka, R. (2019) Salvage Transrectal High-Intensity Focused Ultrasound Therapy for Patients with Recurrence of Vesico-Urethral Anastomosis after Radical Prostatectomy. Open Journal of Urology, 9, 167-179.

https://doi.org/10.4236/oju.2019.910020

Received: September 18, 2019

Accepted: October 26, 2019

Published: October 29, 2019

Copyright $\odot 2019$ by author(s) and Scientific Research Publishing Inc. This work is licensed under the Creative Commons Attribution International License (CC BY 4.0).

http://creativecommons.org/licenses/by/4.0/

c) (i) Open Access

\begin{abstract}
Background: Salvage radiotherapy has been used as the treatment for patients with local recurrence after radical prostatectomy. However, the therapy is time-consuming and it experiences adverse effects of some kind. Simple and less invasive treatment is highly anticipated. Objectives: To evaluate the outcomes of salvage transrectal high-intensity focused ultrasound (HIFU) therapy for patients with localized recurrence of a vesicourethral anastomosis (VUA) after radical prostatectomy. Material and methods: Sixteen patients with suspected local recurrence of a VUA after prostatectomy were treated with HIFU. All patients had prostate-specific antigen (PSA) failure $(>0.2$ $\mathrm{ng} / \mathrm{ml}$ ), positive findings of a VUA with biopsy and/or MRI, TRUS and CT, and no distant metastasis by CT, MRI and bone scintigraphy before HIFU. Recurrence after HIFU was determined by PSA failure $(>0.2 \mathrm{ng} / \mathrm{ml})$, histological findings, metastasis and start of systemic therapies. Results: HIFU treatments were performed in 16 patients, and followed-up for 7 - 159 months (median 46.5). The pre-HIFU PSA levels ranged from 0.318 to 3.1 $\mathrm{ng} / \mathrm{ml}$. Sonication time ranged from $9-42 \mathrm{~min}$. All patients had a decline of PSA after HIFU, and $88 \%$ of the PSA nadir was $<0.2 \mathrm{ng} / \mathrm{ml}$. Recurrence free survival (RFS) rates of 5 year were $31.3 \%$. Nadir PSA was significantly associated with recurrence, whereas initial PSA, pre-HIFU PSA, duration and risk group after prostatectomy were not. There were no intraoperative adverse effects. In the $1-3$ months after HIFU, there was some difficulty voiding in 4 cases (grade 1), urgency incontinence in 3 cases (grade 1 or 2). Conclusion: HIFU therapy for local recurrence after prostatectomy may become a feasible salvage therapeutic option because of its ease and simple procedure. For salvage HIFU therapy, further research and additional follow-up are required to
\end{abstract}


evaluate and correct the diagnosis of recurrence areas and to provide the sufficient sonication.

\section{Keywords}

High-Intensity Focused Ultrasound (HIFU), Prostate Cancer, Recurrence of Vesicourethral Anastomosis (VUA), Radical Prostatectomy, Salvage Therapy

\section{Introduction}

For the past quarter-century, with the high incidence of prostate cancer worldwide, the proportion of early stage prostate cancer has increased. Several treatment options for localized prostate cancer are available including the two standard treatment options, radical prostatectomy, and radiation therapy. Although the treatment outcomes have improved the procedure and devices, the biochemical recurrence rate had not decreased yet [1] [2] [3]. Recently, many alternative and less invasive treatments have been developed for localized prostate cancer [4] [5]. Since the first clinical application of HIFU for the treatment of localized prostate cancer by Madersbacher et al. [6] (using the Sçonablate ${ }^{\mathrm{TM}}$ 200), several investigations of HIFU therapy using Ablatherm or Sonablate systems have been reported for patients with this disease [7] [8] [9]. HIFU is a less invasive technique for thermal ablation of tissue that can induce complete coagulation necrosis of a targeted tumor without requiring surgical exposure or insertion of invasive instruments [10]. Since 2003, we have performed transrectal HIFU therapy for patients with localized prostate cancer, and we have reported the efficacy and safety of HIFU ablation for patients with localized prostate cancer [11] [12]. According to these experiences, we think HIFU therapy has the advantages of fewer complications, the potential for a repeat treatment, simplicity of the procedure, and shorter treatment times [11]. Beginning in 2005, we performed focal HIFU at the VUA for 4 patients with PSA failure without distant metastasis after prostatectomy [13]. Since then, we have experienced an additional 12 cases. Here we retrospectively examined the prognosis and long-term outcomes of the salvage HIFU for total 16 patients with the suspected recurrence of at the VUA.

\section{Methods}

From May 2005 to May 2016 in our Takanobashi central hospital, we performed salvage HIFU in 16 patients (57 - 83 years old). All patients had PSA failure (over $0.2 \mathrm{ng} / \mathrm{ml}$ ) after radical prostatectomy. These patients' characteristics before prostatectomy and before salvage HIFU are shown in Table 1. The median PSA level before radical prostatectomy was $8.4 \mathrm{ng} / \mathrm{ml}$ (range; 4.2 - 18). The postoperative pathological stage ranged $\mathrm{pT} 2 \mathrm{a}-\mathrm{pT} 3 \mathrm{~b}$ and Gleason score ranged 5 - 9. The median follow-up period after prostatectomy in these cases was 18 
months (range; 8 - 144). Over two-thirds of these prostatectomy patients failed within 12 months after treatment using PSA $>0.2 \mathrm{ng} / \mathrm{ml}$ definition. The median PSA level of these 16 patients before HIFU was $0.978 \mathrm{ng} / \mathrm{ml}$ (range; 0.318 - 3.1) without androgen deprivation therapy (ADT) after prostatectomy. No distant metastasis or regional lymph node swelling by CT (including 2 PET CTs), MRI (including 4 multiparametric MRIs) and bone scintigaraphy was found before salvage HIFU (Table 2). However, soft mass lesions at the VUA region were found in 6 patients by CT, 13 by MRI, 4 by TRUS and 2 by urethrocystoscope, which caused us to suspect local recurrence. Positive cancer lesion by biopsy was found in 3 patients.

Table 1. Characteristics of 16 patients with salvage focal HIFU.

\begin{tabular}{|c|c|c|c|c|}
\hline & & & No. pts. & Median (range) \\
\hline \multirow[t]{12}{*}{ Before prostatectomy } & PSA (ng/ml) & & 16 & $8.4(4.2-18)$ \\
\hline & & $3+3$ & 4 & \\
\hline & & $3+4$ & 6 & \\
\hline & Gleason score & $4+3$ & 2 & \\
\hline & & $4+4$ & 2 & \\
\hline & & $4+5$ & 2 & \\
\hline & & T1c & 8 & \\
\hline & Clinical stage & $\mathrm{T} 2 \mathrm{a}$ & 6 & \\
\hline & & $\mathrm{T} 2 \mathrm{~b}$ & 2 & \\
\hline & & Low & 2 & \\
\hline & Risk group (D’Amico) & Intermediate & 10 & \\
\hline & & High & 4 & \\
\hline \multirow[t]{12}{*}{ Before HIFU } & PSA (ng/ml) & & 16 & $0.98(0.318-3.2)$ \\
\hline & & $3+3$ & 2 & \\
\hline & & $3+4$ & 8 & \\
\hline & Gleason score & $4+3$ & 3 & \\
\hline & & $4+4$ & 1 & \\
\hline & & $5+4$ & 2 & \\
\hline & & pT2a & 3 & \\
\hline & Pathological stage & pT2b & 9 & \\
\hline & & pT3a & 3 & \\
\hline & & pT3b & 1 & \\
\hline & $\begin{array}{c}\text { Risk group } \\
\text { (after prostatectomy) }\end{array}$ & Intermediate & 10 & \\
\hline & & High & 6 & \\
\hline
\end{tabular}

HIFU: high-intensity focused ultrasound, PSA: prostate specific antigen, D'Amico: D'Amico classification. 
Table 2. Data of examinations before therapies in patients with salvage HIFU.

\begin{tabular}{ccccccc}
\hline Examination & Local findings & \multicolumn{2}{c}{ Total pts. Positive pts. Negative pts. } & Metastasis & No. pts \\
\hline CT & Soft mass & 14 & 6 & 8 & Distant & 0 \\
MRI & S/o recurrence & 16 & 13 & 3 & Pelvic LN & 0 \\
Bone scintigraphy & Bone metastasis & 4 & 0 & 4 & Bone & 0 \\
Transrectal echo & Soft mass & 14 & 4 & 10 & & \\
Urethrocystoscopy & Regional mass & 12 & 2 & 10 & & \\
Transrectal biopsy & Finding of cancer & 9 & 2 & 7 & \\
TUR-biopsy & Finding of cancer & 5 & 1 & 4 & & \\
\hline
\end{tabular}

CT: computer tomography, MRI: magnetic resonance imaging, TUR: transrectal resection, LN: lymph node.

Fifteen patients were treated using Sonablate $500^{\circ}$ and/or version 4 (Sonacare Medical, Inc., Indianapolis, IN, USA) device under spinal anesthesia, and one with caudal anesthesia. HIFU therapy was performed using the standard transrectal procedure [14]. In order to confirm the position of the external sphincter at the time of the HIFU treatment, we placed biopsy forceps as a marker at the distal portion of the external sphincter under urethroscopic visualization [14]. We performed HIFU sonication on the VUA region from the proximal portion of the external sphincter to the bladder neck under ultrasound visualization (Figure 1). Recurrence after salvage HIFU was determined based on PSA failure (PSA $>0.2 \mathrm{ng} / \mathrm{ml}$ ), histological findings, metastasis and start of ADT. Recurrence free survival (RFS) rate was calculated using Kaplan-Meier curves and a log-rank test was used to evaluate differences between these curves. Mann-Whitney test was used to evaluate statistical difference of two groups. P-value of $<0.05$ was considered to indicate statistically significant differences. Patient status and treatment-related complications in the Japanese version of the National Cancer Institute-Common Toxicity Criteria version 4.0 [15] were evaluated.

All patients received informed consent of the diagnosis and treatments for suspected recurrence of a VUA lesion. The patients who chose HIFU therapy were provided with the informed consent for particular HIFU treatment and agreed to pay privately for the uninsured therapy in Japan, and the institutional review board for Takanobashi Central Hospital approved these studies.

\section{Results}

HIFU therapy was performed in 16 patients. Intraoperative and perioperative results are shown in Table 3. The median HIFU exposure time was $28 \mathrm{~min}$. (range; 9 - 42). The median hospital stay was 2 days (range; 2 - 7) and the median periods of catheterization were 5.5 days (range; 4 - 21). There were no adverse effects observed in the period from HIFU treatment to removal of the indwelling catheter. 

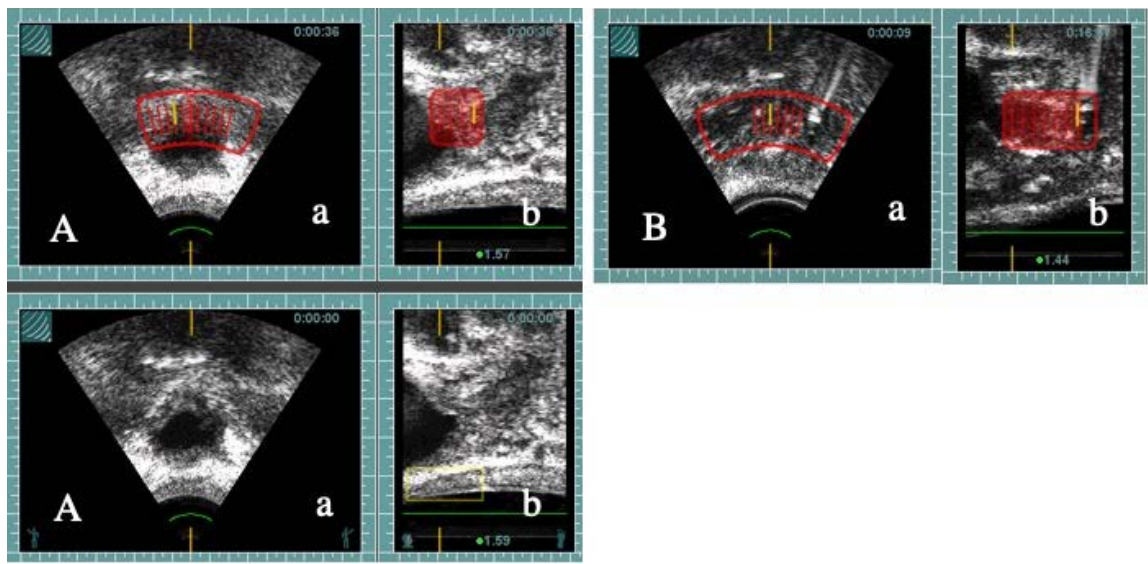

Figure 1. Ultrasound images during HIFU. (A) Sonication field in upper half of the urethra in case 2. (B) Marking the distal portion of the external sphincter with a biopsy forceps. (a) Sector section view (b) Linear section view.

Table 3. Intraoperative and perioperative results of HIFU therapy.

\begin{tabular}{ccc}
\hline No. of patients: & 16 \\
\hline No. of sessions: & 16 times & \\
Anesthesia: & Spinal 15 times, caudal 1 time & \\
HIFU exposure time: & Median 28 min. & Range $9-42$ min. \\
Hospital stay (post OP): & 2 days & $2-7$ days \\
Catheterization period: & 5.5 days & $4-21$ days \\
Adverse effects: & None & \\
\hline
\end{tabular}

The median follow-up period of this study was 46.5 months (range; 7 - 159). As shown in Table 4, the median PSA nadir after HIFU was $0.088 \mathrm{ng} / \mathrm{ml}$ (range; $0.008-0.789$ ) at 1.5 median month (range; $1-21$ ), and $88 \%$ of these PSA were $<0.2 \mathrm{ng} / \mathrm{ml}$. The curve of RFS rates were analyzed using the Kaplan-Meier method with PSA level $>0.2$ indicating recurrence in Figure 2(A). The RFS rates of 1, 2, 3 and 5 year were $50 \%, 37.5 \%, 31.3 \%$ and $31.3 \%$. Patients were categorized according to risk group with initial PSA, pathological Gleason score and T-stage in Figure 2(B). There was no difference in the RFS between the intermediate risk (30\%) and the high risk (33\%) group. Of the 16 patients with salvage HIFU, 4 patients' PSAs were under $0.2 \mathrm{ng} / \mathrm{ml}$ at the latest PSA, one patient's PSA was $<0.2 \mathrm{ng} / \mathrm{ml}$ until 115 months after HIFU, and 11 patients' PSAs were over 0.2 $\mathrm{ng} / \mathrm{ml}$ until 36 months after HIFU. A small mass was detected by CT and/or MRI before HIFU recurred in ten cases (77\%) of the 13 patients. We compared the five effective cases with the early recurrence 11 cases. Although there was no difference in initial PSA $(P=0.141)$, pretreatment PSA $(P=0.257)$ and the time to salvage HIFU after prostatectomy $(\mathrm{P}=0.363)$ between the effective 5 cases and the recurrent 11 cases, we recognized significant difference $(P=0.014)$ in the nadir PSA after HIFU. 
Table 4. Results of HIFU therapy in 16 patients with recurrence of vesicourethral anastomosis.

\begin{tabular}{|c|c|c|c|}
\hline Follow up period after HIFU & \multicolumn{2}{|c|}{7 - 159 months (median 46.5) } & No. of patients \\
\hline \multirow[t]{6}{*}{ PSA nadir (PSA ng/ml) } & \multicolumn{2}{|c|}{$0.008-0.789$ (median 0.088$)$} & \\
\hline & \multicolumn{2}{|c|}{1 - 21 months (median 1.5) } & \\
\hline & \multicolumn{2}{|c|}{$<0.01$} & 4 \\
\hline & \multicolumn{2}{|c|}{$0.01-<0.2$} & 10 \\
\hline & \multicolumn{2}{|c|}{$0.2-<0.4$} & 1 \\
\hline & \multicolumn{2}{|c|}{$\geq 0.4$} & 1 \\
\hline \multirow[t]{5}{*}{ Disease free survival rate } & 1 year & $50.0 \%$ & \\
\hline & 2 year & 37.5 & \\
\hline & 3 year & 31.3 & \\
\hline & 4 year & 31.3 & \\
\hline & 5 year & 31.3 & \\
\hline \multicolumn{4}{|l|}{ PSA result of salvage HIFU } \\
\hline & \multicolumn{2}{|c|}{$<0.2$} & 4 \\
\hline & \multicolumn{2}{|c|}{$<0.4$ over 24 months } & 5 \\
\hline & \multicolumn{2}{|c|}{$<0.4$ under12 months } & 4 \\
\hline & \multicolumn{2}{|c|}{$>0.4$ under 12 months } & 3 \\
\hline \multicolumn{4}{|c|}{ Adverse effects at $1-3$ months after HIFU } \\
\hline & \multicolumn{2}{|c|}{ Difficult voiding } & G1 2, G2 3 \\
\hline & \multicolumn{2}{|c|}{ Urinary incontinence } & G1 2, G2 1 \\
\hline & \multicolumn{2}{|c|}{ Recto-urethral fistula } & 0 \\
\hline
\end{tabular}

G: Grade of CTCAE v4.

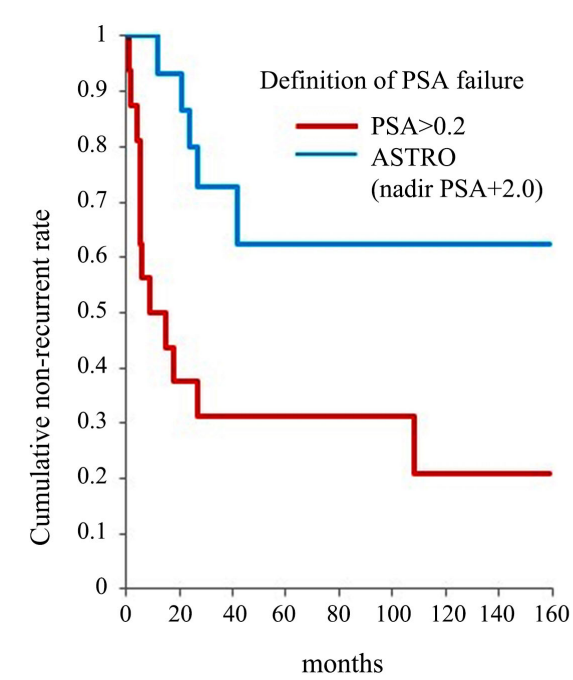

(A)

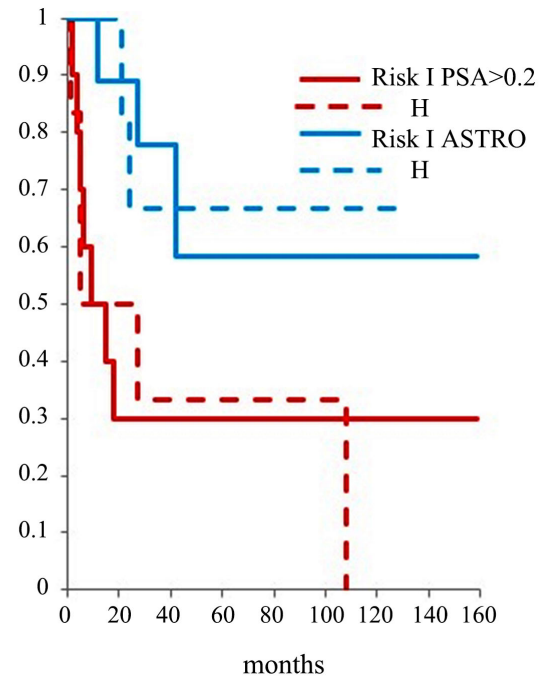

(B)

Figure 2. Non-recurrent curves in 16 cases with salvage HIFU. (A) According definition of PSA failure; (B) According risk group with iPSA, p-Gleason score and p-Stage. 
The changes of the PSA levels in non-recurrent cases (cases No. 4, 8 and 9) are shown in Figure 3. Their PSA stayed under $<0.2 \mathrm{ng} / \mathrm{ml}$ for the follow-up periods. Figure 4 shows the changes of the PSA in non-recurrent within 2 years (cases No. 1 and 13). Their PSA remained $<0.4 \mathrm{ng} / \mathrm{ml}$ for over 3 years. A temporary rise was usually observed in the PSA level in all patients on the first day after HIFU and a rapid decrease of PSA was seen thereafter.

Adverse effects at 1 - 3 months after HIFU (Table 4) were difficulty with voiding in 4 patients (grade-1) and urinary urgency or incontinence was observed in 3 cases (grade-1; 2 , grade- $2 ; 1$ ).

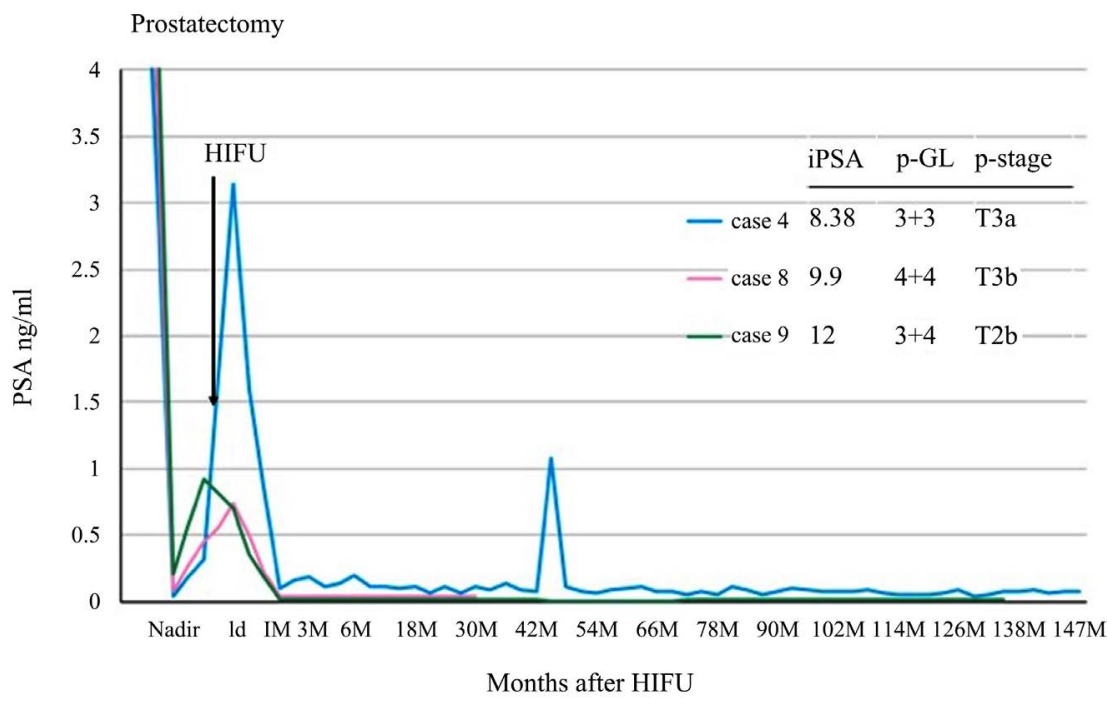

Figure 3. Changes in PSA levels following salvage HIFU therapy in patients with excellent outcome. iPSA: initial PSA -GL: pathological Gleason's score p-stage: pathological stage.

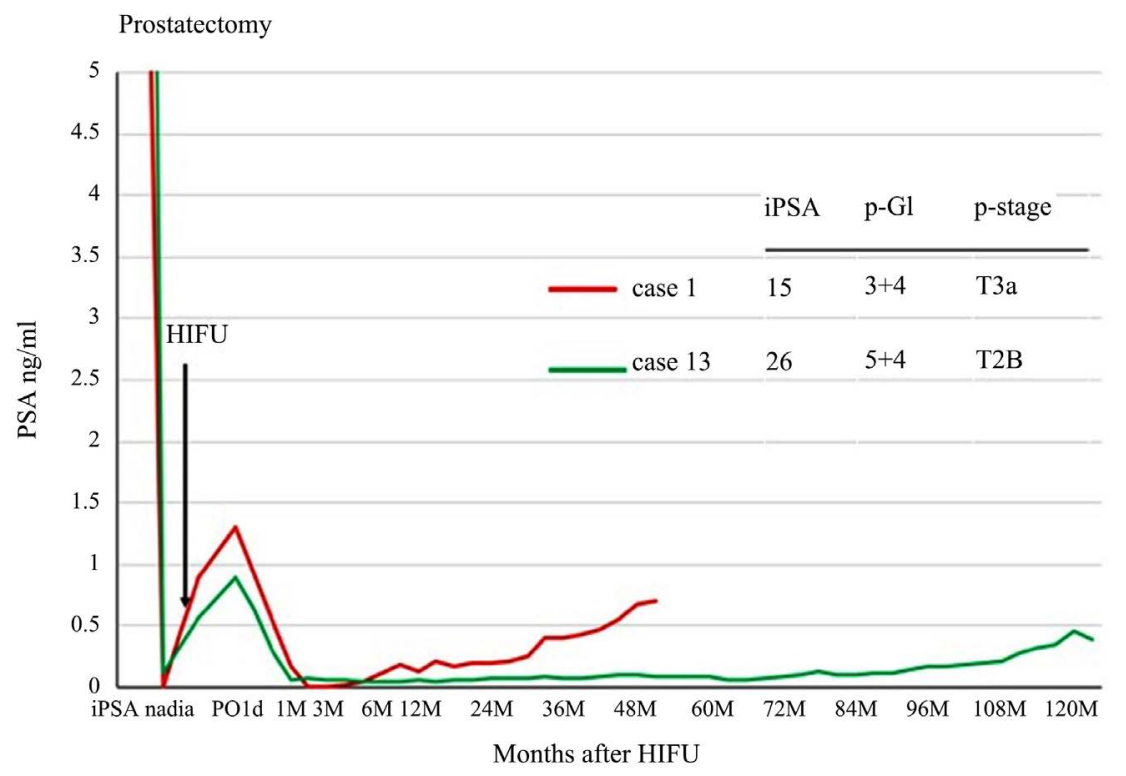

Figure 4. Changes in PSA levels following salvage HIFU therapy in patients with good outcome. 
For the prognosis of these salvage HIFU patients, 6 of 12 patients with PSA failure underwent ADT, 3 underwent re-treatment with HIFU, one was followed-up without therapy and two were unknown. No patients died of prostate cancer, but two died of cardiovascular disease and three patients were lost to follow up. A recto-urethral fistula was not observed in this series.

\section{Discussion}

There are some salvage therapies for recurrence after radical treatment of localized prostate cancer [16] [17] [18]. For salvage HIFU therapy, although there are many reports for radio-recurrent prostate cancer in recent years [19] [20] [21], there are only a few reports [22] [23] for recurrence after prostatectomy available besides our reports [13] [14] and those of Murota-Kawano [24]. After our first report of salvage HIFU therapy for four patients after prostatectomy [13], we performed salvage focal HIFU on lesions at the VUA in a total of 16 cases. The advantages of salvage HIFU therapy as well as whole grand HIFU for primary prostate cancer include the following [10]: no bleeding, less infection, ease of procedure, shorter treatment times, and the possibility of administering repeat treatments. As shown in Figures 3-5, a temporary rise is observed in the PSA level of nearly all patients on the first day after HIFU. These PSA changes appear to confirm the fact that the residual prostate tissue was destroyed in the sonication fields. Further, the rapid decrease of PSA after a temporary rise indicates the effectiveness of HIFU therapy.

The biochemical recurrence free survival (BRFS) of the salvage HIFU after radiation therapy was based on Phoenix definition. In the two large volume reports [20] [21] about salvage HIFU after failed radiotherapy, the BRFS rates were $48 \%$ at 3 years and $49 \%$ at 5 years for the entire group. The BRFS rates were $100 \%, 61 \%$ and $32 \%$ at 3 years and $58 \%, 51 \%$ and $22 \%$ at 5 years in the low-, intermediate- and high-risk groups on pre-salvage HIFU, respectively. Conversely, the salvage HIFU after prostatectomy results in other reports [22] [23], effectiveness of this therapy was defined as $<0.4 \mathrm{ng} / \mathrm{ml}$ PSA level or PSA nadir level. The success rate of these reports at 4 years was $45 \%-47 \%$. Although there are differences of proportion of stage, risk group and duration of follow-up as compared to these reports [22] [23], our RFS rates using the criteria of $0.2 \mathrm{ng} / \mathrm{ml}$ PSA were $31.3 \%$ at 3 or 5 years after HIFU. With PSA $<0.4 \mathrm{ng} / \mathrm{ml}$, our RFS rate was $43.8 \%$ and $31.3 \%$ at 3 and 5 years after HIFU. On the other hand, our RFS rate was $72.7 \%$ and $62.3 \%$ by the ASTRO definition. Our outcomes were similar to the RFS rate of these reports [22] [23].

The main complications for salvage HIFU after radiotherapy are urethral and/or bladder neck stricture at $8 \%-18 \%$, and RUF at $2 \%-2.3 \%$ [20] [21]. For salvage HIFU after prostatectomy in other reports [22] [23], although urethral stricture rate was similar $(5 \%-10 \%)$, the urinary incontinence was higher $(21 \%$ - 25\%) and RUF was not observed. At 1 - 3 months after HIFU, difficulty in voiding and urinary urgency or incontinence was similar (25\% and $19 \%$ respectively). 


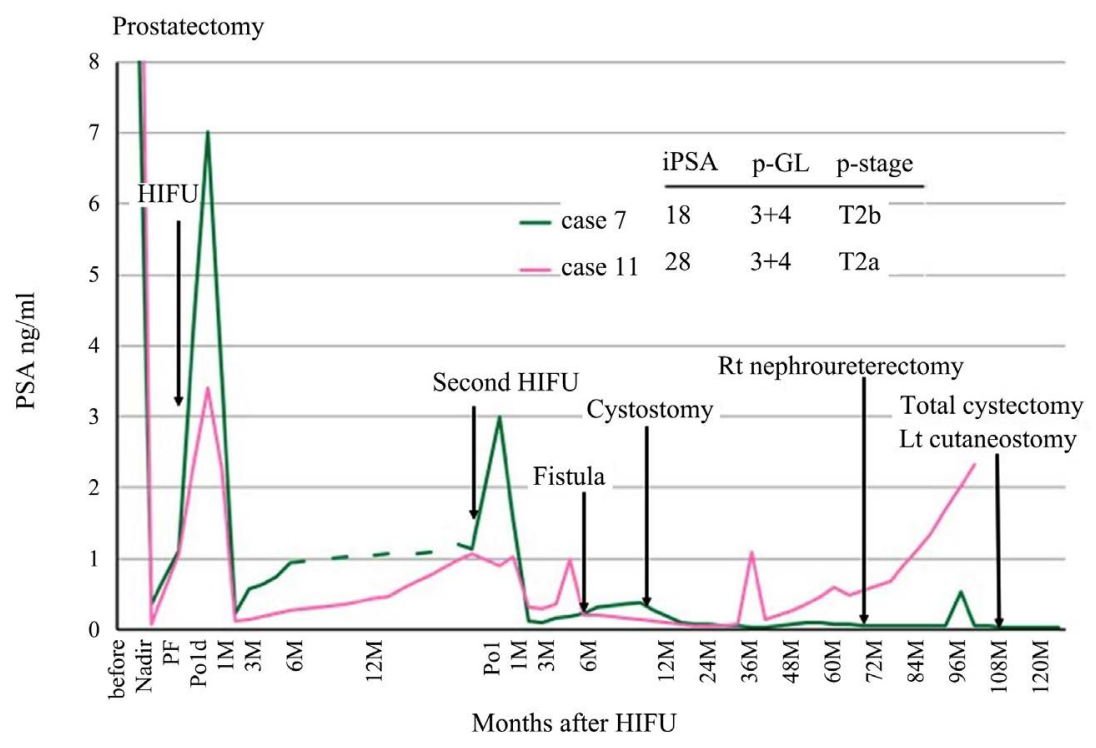

Figure 5. Changes in PSA levels following second salvage HIFU therapy in patients with recto-urethral fistula.

Although a recto-urethral fistula (RUF) was not observed in this series, we experienced a RUF in 2 of the 3 patients with a second HIFU treatment. As these adverse events were important, we are presenting the two cases with serious side effects. The changes of PSA levels in the patients (case No. 7, 11) are shown in Figure 5. They underwent a second salvage HIFU treatment because of early recurrence, and a recto-urethral fistula occurred after removal of the urethral catheter. Though they had suprapubic cystostomy, an artificial colostomy and trans-rectal closure, the RUF were not closed completely during follow-up. Patient (No. 7) also underwent a TUR for bladder tumor, and a right nephroureterectomy for ureteral cancer after the second HIFU, and then a total cysto-urethrectomy and left cutaneous ureterostomy due to the recurrence of bladder cancer. The fistula almost healed by the time of the total cystectomy, and no adenocarcinoma was found in the VUA. The RUF of second patient (No. 11) did not close during follow-up. He has undergone ADT and his PSA is still under 2 $\mathrm{ng} / \mathrm{ml}$.

We inferred from the experience of our two patients with RUF that the RUF may have been caused by the second HIFU with its high power energy and the delay of treatments for dysuria. Topazio et al. [25] reported success for RUF with conservative treatment. But our patients could not obtain complete closure even with surgical procedures.

We performed a second salvage HIFU treatment for 3 patients with recurrence, and followed them-up from 112 to 144 months. Although all patients had recurrence, one patient had PSA $<0.2$ for more than 4 years and the patient (No. 7) with RUF had PSA $<0.3 \mathrm{ng} / \mathrm{ml}$ for more than 4 years and $<0.1 \mathrm{ng} / \mathrm{ml}$ after cystectomy. Though we cannot evaluate the effectiveness of re-treatment with salvage HIFU because there were only three cases, users should be aware of the risk of RUF. 
The limitation in our retrospective study is that there were many patients without biopsy-confirmed local recurrence. As for the histological confirmation, it was difficult to confirm by early biopsy after prostatectomy, especially with PSA $<1.0 \mathrm{ng} / \mathrm{ml}[26]$ or with PSA $<0.5 \mathrm{ng} / \mathrm{ml}$ and negative digital rectal examination [27]. In our cases with no malignancy by biopsy, it is necessary to confirm with another test, such as digital rectal palpation, TRUS or MRI [28]. Recently, fusion biopsy with TRUS and multiparametric MRI is recommended for diagnosis or recurrence after radical therapy of prostate cancer [29]. Therefore, we performed these from the proximal portion of the external sphincter to the bladder neck by the placement of a biopsy forceps as a marker, which was inserted to the distal portion of the external sphincter (Figure 1(B)).

In the latest two cases of salvage HIFU, there was suspicion of recurrence on the VUA region by multiparametric MRI, but these lesions could not be proven by transrectal biopsy. In one of the cases discovered by multiparametric MRI, we found that the positive findings disappeared by MRI at 7 months after HIFU. After that, when the PSA rose over 2.0 at 26 months after HIFU, the positive finding appeared in the proximity of the residual seminal vesicle located by MRI.

Asimakopoulos et al. [22] reported on 19 patients that those patients with lower Gleason scores and lower PSA values had a better outcome than those patients with higher scores and values. In our patients, there was no difference in the RFS rate between the intermediate and the high risk groups. In the comparison with effective cases and early recurrent cases, there was significant difference only in the nadir PSA after HIFU. From these results, we consider that the effectiveness of salvage HIFU is due to sufficient sonication of recurrence areas rather than PSA levels or malignant grade. So it is critical to correctly diagnose the area of recurrence and perform sufficient sonification. Although the predictive factor is a nadir PSA, we cannot determine in advance the patients that will respond favorably to HIFU.

In the cases with no malignancy determined by biopsy, it is necessary to confirm with TRUS and multiparametric MRI. However in the case of prostatecto$\mathrm{my}$, it is hard to diagnosis because of minimal tumor mass (PSA $<1.0 \mathrm{ng} / \mathrm{ml}$ ) [26] [27] [30]. Moreover, HIFU therapy is sensitive surrounding blood flow or urine for achieving sufficient temperature [6] [10]. It is also critical to determine the accurate distance from the rectal mucosa to the VUA.

HIFU therapy for local recurrence after prostatectomy may become a feasible therapeutic salvage option because of its easy and short procedure time. As our study was a retrospective analysis with a low volume cases, further research and additional follow-up are required to evaluate this salvage therapy. Moreover for the best outcomes, correct diagnosis of recurrence areas, sufficient sonication and careful follow-up are necessary.

\section{Conflicts of Interest}

The authors declare no conflicts of interest regarding the publication of this paper. 


\section{References}

[1] Menon, M., Bhandari, M., Gupta, N., Lane, Z., Peabody, J.O., Gogers, C.G., Sammon, J., Siddiqui, S.A. and Diaz, M. (2010) Biochemical Recurrence Following Robot-Assisted Radical Prostatectomy: Analysis of 1384 Patients with a Median 5-Year Follow-Up. European Urology, 58, 838-846. https://doi.org/10.1016/j.eururo.2010.09.010

[2] Busch, J., Stephan, C., Herold, A., Erber, B., Kempkensteffen, C., Hinz, S., Lein, M., Weikert, S., Miller, K. and Magheli, A. (2012) Long-Term Oncological and Continence Outcomes after Laparoscopic Radical Prostatectomy: A Single-Centre Experience. BJU International, 110, E985-E990. https://doi.org/10.1111/j.1464-410X.2012.11279.x

[3] Golbari, N.M. and Katz, A.E. (2017) Salvage Therapy Options for Local Prostate Cancer Recurrence after Primary Radiotherapy: A Literature Review. Current Uroogy Reports, 18, 63. https://doi.org/10.1007/s11934-017-0709-4

[4] Zelefsky, M.J., Kuban, D.A., Levy, L.B., Potters, L., Beyer, D.C., Blasko, J.C., Moran, B.J., Ciezki, J.P., Zietman, A.L., Pisansky, T.M., Elshaikh, M. and Horwits, E.M. (2007) Multi-Institutional Analysis of Long-Term Outcome for Stage T1-T2 Prostate Cancer Treated with Permanent Seed Implantation. International Journal of Radiation Oncology, Biology, Physics, 67, 327-333. https://doi.org/10.1016/j.ijrobp.2006.08.056

[5] Cohen, J.K., Miller, R.J., Ahmed, S. and Baust, J. (2008) Ten-Year Biochemical Disease Control for Patients with Prostate Cancer Treated with Cryosurgery as Primary Therapy. Urology, 71, 515-718. https://doi.org/10.1016/j.urology.2007.09.059

[6] Madersbacher, S., Pedevilla, M., Vinger, L., Susani, M. and Merberger, M. (1955) Effect of High-Intensity Focused Ultrasound on Human Prostate Cancer in Vivo. Cancer Research, 55, 3346-3351.

[7] Ganzer, R., Fritsche, H.M., Brandtner, A., Brundl, J., Koch, D., Wieland, W.F. and Blana, A. (2013) Fourteen-Year Oncological and Functional Outcomes of High-Intensity Focused Ultrasound in Localized Prostate Cancer. BJU International, 112, 322-329. https://doi.org/10.1111/j.1464-410X.2012.11715.x

[8] Crouzet, S., Chapelon, J.Y., Rouviere, O., Mege-Lechevallier, F., Colombel, M., Tonoli-Cates, H., Martin, X. and Gelet, A. (2014) Whole-Gland Ablation of Localized Prostate Cancer with High-Intensity Focused Ultrasound Oncologic Outcomes and Morbidity in 1002 Patients. European Urology, 65, 907-914.

https://doi.org/10.1016/j.eururo.2013.04.039

[9] Uchida, T., Tomonaga, T., Kim, H., Nakano, M., Shoji, S., Nagata, Y. and Terachi, T. (2015) Improved Outcomes with Advancements in High Intensity Focused Ultrasound Devices for the Treatment of Localized Prostate Cancer. Journal of Urolo$g y$, 193, 103-110. https://doi.org/10.1016/j.juro.2014.07.096

[10] Shoji, S., Tomonaga, T., Kim, H., Nakano, M. and Uchida, T. (2014) High-Intensity Focused Ultrasound for Prostate Cancer. Japanese Journal of Medical Ultrasonics, 41, 717-726. https://doi.org/10.3179/jjmu.JJMU.R.19

[11] Inoue, Y., Goto, K., Hayashi, T. and Hayashi, M. (2011) Transrectal High-Intesity Focused Ultrasound for Treatment of Localized Prostate Cancer. International Journal of Urology, 18, 358-362. https://doi.org/10.1111/j.1442-2042.2011.02739.x

[12] Hayashi, M., Oka, K. and Inoue, K. (2015) Long-Term Outcomes of Transrectal High-Intensity Focused Ultrasound for Localized Prostate Cancer. Japanese Journal of Endourology, 28, 322-330.

[13] Hayashi, M., Shinmei, S. and Asano, K. (2007) Transrectal High-Intensity Focused 
Ultrasound for Patients with Biochemical Failure after Radical Prostatectomy. International Journal of Urology, 14, 1048-1050. https://doi.org/10.1111/j.1442-2042.2007.01880.x

[14] Hayashi, M., Goto, K., Hayashi, T. and Inoue, Y. (2009) Experience of Transrectal High-Intensity Focused Ultrasound for Patients with Localized Recurrence of around Vesico-Urethral Anastomosis after Radical Prostatectomy. Japanese Journal of Endourology and ESWL, 22, 301-308.

[15] JCOG (2010) Common Terminology Criteria for Adverse Events (CACAE) Version 4.0.

[16] Jeffrey, A.C., Alan, W.P., Theodore, L.D. and Patrick, C.W. (1998) Long-Term Results of Radiation Therapy for Prostate Cancer Recurrence Following Radical Prostatectomy. Journal of Urology, 159, 173-178. https://doi.org/10.1016/S0022-5347(01)64047-3

[17] Lederman, G.S., Cavanagh, W., Albert, P.S., Israeli, R., Lessing, J., Savino, M. and Volpicella, F. (2001) Retrospective Stratification of a Consecutive Cohort of Prostate Cancer Patients Treated with a Combined Regimen of External-Beam Radiotherapy and Brachytherapy. International Journal of Ridiation Oncology Biology Physiolo$g y$, 49, 1297-1303. https://doi.org/10.1016/S0360-3016(00)01442-5

[18] Touma, N.J., Izawa, J.I. and Chin, J.L. (2005) Current Status of Local Salvage Therapies Following Radiation Failure for Prostate Cancer. Journal of Urology, 173, 373-379. https://doi.org/10.1097/01.ju.0000150627.68410.4d

[19] Murat, F.J., Poissonnier, L., Rabilloud, M., Belot, A., Bouvier, R., Rouviere, O., Chapelon, J.Y. and Gelet, A. (2009) Mid-Term Results Demonstrate Salvage High-Intensity Focused Ultrasound (HIFU) as an Effective and Acceptably Morbid Salvage Treatment Option for Locally Radiorecrrent Prostate Cancer. European Urology, 55, 640-647. https://doi.org/10.1016/j.eururo.2008.04.091

[20] Kanthabalan, A., Peters, M., Van Vulpen, M., McCartan, N., Hindley, R.G., Emara, A., Moore, C.M., Arya, M., Emberton, M. and Ahmed, U. (2017) Focal Salvage High-Intensity Focused Ultrasound in Radio Recurrent Prostate Cancer. BJU International, 120, 246-256. https://doi.org/10.1111/bju.13831

[21] Crouzet, S., Blana, A., Murat, F.J., Pasticier, G., Brown, S.C.W., Conti, G.N., Ganzer, R., Chapet, O., Gelet, A., Chaussy, C.G., Robertson, N.N., Thuroff, S. and Ward, J.F. (2017) Salvage High-Intensity Focused Ultrasound (HIFU) for Locally Recurrent Prostate Cancer after Failed Radiation Therapy: Multi-Institutional Analysis of 418 Patients. BJU International, 119, 896-904. https://doi.org/10.1111/bju.13766

[22] Asimakopoulos, A.D., Miano, R., Virgili, G., Vespasiani, G. and Finazzi, A.E. (2012) HIFU as Salvage First-Line Treatment for Palpable, TRUS-Evidenced, Biopsy-Proven Locally Recurrent Prostate Cancer after Radical Prostatectomy: A Pilot Study. Urology Oncology, 30, 577-583. https://doi.org/10.1016/j.urolonc.2010.08.019

[23] Palermo, G., Totaro, A., Sacco, E., Foschin, N., Gulino, G., Racioppi, M., Bassi, P. and Pinto, F. (2017) High Intensity Focused Ultrasound as First Line Salvage Therapy in Prostate Cancer Local Relapse after Radical Prostatectomy: 4-Year Follow-Up Outcomes. Minerva Urology Nefrology, 69, 93-100.

[24] Murota-Kawano, A., Nakano, M., Hongo, S., Shoji, S., Nagata, Y. and Uchida, T. (2009) Salvage High-Intensity Focused Ultrasound for Biopsy-Confirmed Local Recurrence of Prostate Cancer after Radical Prostatectomy. BJU International, 105, 1642-1645. https://doi.org/10.1111/j.1464-410X.2009.08990.x

[25] Topazio, L., Perugia, C. and Finazzi-Agro, E. (2013) Conservative Treatment of a 
Recto-Urethral Fistula Due to Salvage HIFU for Local Recurrence of Prostate Cancer, 5 Years after Radical Prostatectomy and External Beam Radiotherapy. BMJ Case Reports, 2012, pii: bcr0320126115. https://doi.org/10.1136/bcr.03.2012.6115

[26] Shekarriz, B., Upadhyay, J., Wood, D.P., Hinman, J., Raasch, J., Cummings, G.D., Grignon, D. and Littrup, P.J. (1999) Vesicourethral Anastomosis Biopsy after Radical Prostatectomy: Predictive Value of Prostate-Specific Antigen and Pathologic Stage. Urology, 54, 1044-1048. https://doi.org/10.1016/S0090-4295(99)00351-9

[27] Saleen, M.D., Sanders, H., Abu, E.N.M. and El-Gally, R. (1998) Factors Predicting Cancer Detection in Biopsy of the Prostatic Fossa after Radical Prostatectomy. Urology, 51, 283-286. https://doi.org/10.1016/S0090-4295(97)00509-8

[28] Casciani, E., Polettini, E., Carmenini, E., Floriani, I., Masselli, G., Bertini, L. and Gualdi, G.F. (2008) Endorectal and Dynamic Contrast-Enhanced MRI for Detection of Local Recurrence after Radical Prostatectomy. American Journal of Roentgenology, 190, 1187-1192. https://doi.org/10.2214/AJR.07.3032

[29] Shoji, S., Hiraiwa, S., Ogawa, T., Kawakami, M., Nakano, M., Hashida, K., Sato, Y., Hasebe, T., Uchida, T. and Tajiri, T. (2017) Accuracy of Real-Time Magnetic Resonance Imaging-Transrectal Ultrasound Fusion Image-Guided Transperineal Target Biopsy with Needle Tracking with a Mechanical Position-Encoded Stepper in Detecting Significant Prostate Cancer in Biopsy-Naïve Men. International Journal of Urology, 24, 288-294. https://doi.org/10.1111/iju.13306

[30] Connolly, J.A., Shinohara, K., Presti, J.C. and Carroll, P.R. (1996) Local Recurrence after Radical Prostatectomy: Characteristics in Size, Location, and Relationship to Prostate-Specific Antigen and Surgical Margins. Urology, 47, 225-231. https://doi.org/10.1016/S0090-4295(99)80421-X

\section{Abbreviations \& Acronyms}

$\mathrm{ADT}=$ androgen deprivation therapy

ASTRO = American Society for Therapeutic Radiology and Oncology

BRFS = biochemical recurrence free survival

$\mathrm{CT}=$ computed tomography

HIFU = high-intensity focused ultrasound

$\mathrm{MRI}=$ magnetic resonance imaging

PSA $=$ prostate-specific antigen

RFS $=$ recurrence free survival

RUF $=$ recto-urethral fistula

TRUS $=$ transrectal ultrasound

TU-biopsy $=$ transurethral biopsy

VUA $=$ vesicourethral anastomosis 